\title{
REVISITA AL TERCER CASO DE VERTICALIDAD DE JOHN MURRA EN LAS COSTAS DE LOS ANDES CENTRALES Y CENTRO SUR
}

\author{
THE THIRD CASE OF JOHN MURRA'S VERTICALITY REVISITED ON THE \\ COASTS OF THE CENTRAL AND SOUTH-CENTRAL ANDES
}

\author{
Calogero M. Santoro ${ }^{1,2,3}$, Tom D. Dillehay ${ }^{4,5}$, Jorge Hidalgo ${ }^{6}$, Daniela Valenzuela R.7, \\ Álvaro L. Romero G. ${ }^{8}$, Francisco Rothhammer ${ }^{1,3,9}$ y Vivien G. Standen ${ }^{2}$
}

\begin{abstract}
A partir de la confrontación de datos arqueológicos, etnohistóricos y bioantropológicos de los períodos Intermedio Tardío y Tardío (ca. 1.000-1.530 d.C.), se evaluó si las poblaciones del valle de Lluta se organizaron económicamente bajo el Tercer Caso de Verticalidad de John Murra. Para ello centramos la atención en el sector chaupiyunga, etnocategoría geográfica de alta valorización en el sistema vertical de pisos ecológicos entre la costa y el altiplano. Se caracterizó la situación cultural en esta cuenca ubicada en la subárea Valles Occidentales del Centro Sur Andino y se comparó con la situación del valle de Chillón, Andes Centrales.

El panorama arqueológico en ambas zonas integra una amplia variedad de componentes culturales que, en el caso del Lluta, comprende una mezcla de elementos de tierras bajas, sierra, altiplano e Inka, mientras que en el Chillón confluyen rasgos costeros, chaupiyunga y altoandinos. En el caso del Lluta, se agregan rasgos funerarios y de arte rupestre. Para ambas zonas, pero con distintos niveles de especificidad las fuentes etnohistóricas también señalan la concurrencia de varias entidades sociales. Lo importarte es que este heterogéneo escenario del chaupiyunga se repite en otras zonas chaupiyunga del sur de Perú y contrasta con los sectores bajos de los valles que tienden a ser culturalmente más homogéneos.

El estado actual del conocimiento arqueológico no permite señalar con precisión el o los mecanismos concretos de interacción o complementariedad que expliquen la variabilidad observada en el registro arqueológico. Primeramente, éste no se corresponde con la idea de islas multiétnicas diferenciadas entre sí por conjuntos de rasgos propios. Por el contrario, los restos materiales de los diferentes componentes o referentes culturales aparecen mezclados en cada uno de los sitios, por lo que pueden representar varios mecanismos de interacción social que funcionaron paralela y secuencialmente.

Se concluye que el chaupiyunga fue un espacio multiétnico, cohabitado, visitado y/o liderado por grupos sociales de distinto origen, que se hicieron presente en este ambiente productivo bajo distintos mecanismos de complementariedad o de interacción, que pudo incluir entre otros verticalidad (con sus modalidades de verticalidad costera, microverticalidad descentralizada, archipiélago vertical centralizado), horizontalidad, simples operaciones de intercambio de productos, protección militar y alianzas matrimoniales a través del intercambio de esposas o esposos.
\end{abstract}

Palabras claves: verticalidad, complementariedad, multietnicidad, Andes Centrales y Centro Sur, Intermedio Tardío, Tardío o Inka, Colonial temprano.

Archaeological, ethnohistorical, and bioanthropological data from Late Intermediate and Late Periods (ca. A.D. 1,000-1,530) was cross-examined to evaluate whether people of the Lluta Valley organized their economy under the Third Case of John Murra model of Verticality. To do this, we focused on the chaupiyunga sector a geographic ethnocategory of high valuation in the system of the ecological tiers between the coast and highlands, for its productive qualities and geographic connectivity. The cultural composition of this basin located in the western valleys sub area, of the South Central Andes was compared of what has been observed in the Chillón valleys, in the Central Andes.

The archaeological arrangement in both zones combines a variety of cultural ceramic style components. While the Lluta valley shows a mixture of items from the lowlands, sierra, altiplano and Inka, the Chillón basin integrates coastal, chaupiyunga and highAndean elements. For the Lluta case funerary and rock ark features. XVI and XVII century ethnohistorical sources, of different level

1 Instituto Alta Investigación, Universidad de Tarapacá, Casilla 6-D, Arica, Chile. calogero_santoro@yahoo.com

2 Departamento de Antropología, Universidad de Tarapacá, Casilla 6-D, Arica, Chile. vivien.standen@ gmail.com, vstanden@uta.cl

3 Centro de Investigaciones del Hombre en el Desierto, Universidad de Tarapacá, Arica, Chile.

4 Department of Anthropology, Vanderbilt University, USA. tom.d.dillehay@ vanderbilt.edu

5 Instituto de Ciencias Sociales, Universidad Austral de Chile, Valdivia, Chile.

6 Departamento de Ciencias Históricas, Facultad de Filosofía y Humanidades, Universidad de Chile, Santiago, Chile. hidalgol@uchile.cl, jorgehidalgolehuede@gmail.com

7 Programa de Doctorado en Antropología, Instituto de Investigaciones Arqueológicas y Museo, Universidad Católica del Norte, San Pedro de Atacama, Chile. dani.valenzu@gmail.com

8 Comisión Asesora de Monumentos Nacionales de Arica y Parinacota, Arica, Chile. alrogu@ yahoo.com

9 Programa de Genética Humana, ICBM, Facultad de Medicina, Universidad de Chile. frothham@med.uchile.cl 
of specificity, coincide for both regions the interrelation of several social entities. It is important to note that the heterogeneous scenario of the chaupiyunga is observed in similar ecological zones in Southern Peru, which contrasts with the homogeneity of the lower sections of the valleys.

The state of the art does not allow to precise the mechanisms of interaction and complementarity to explain the variability of the archaeological records. First there is not correspondence with the idea of multiethnic "islands" differentiated by particular set features among themselves. On the contrary, the material is mixed in each of the studied sites, which seem to mean that several mechanisms of interaction were simultaneously or sequentially functioning.

We conclude that chaupiyunga was a multiethnic ecological space co-habited, visited and or lead by social groups of diverse origin that access to this productive zone under different mechanisms of complementarity and interaction, which may have included verticality (with is modalities of coastal verticality, decentralized micro verticality, centralized vertical archipelago), horizontality, simple exchange operations, military protection, married alliances through the exchange of spouses.

Key words: Verticality, complementarity, Central and South Central Andes, Late Intermediate Period, Late Horizon and Early Colonial Period.

En el clásico artículo que acompaña la Visita de la Provincia de León de Huánuco en 1562. Iñigo Ortiz de Zúniga, Visitador, Murra (1972) le dio forma al modelo "archipiélagos verticales", inspirado en el funcionamiento del reino Lupaqa que deriva de la Visita hecha a la provincia de Chucuito por Garci Diez de San Miguel en el año 1567 (Murra 1964a, 1964b, 1968). En la presentación de las variaciones geográficas y escalas del modelo, Murra señaló:

La temprana desaparición física, genocídica, de las etnias costeñas hace difícil la tarea de aclarar si es que los "archipiélagos verticales" existían o no en la costa. Dos hechos nos dan esperanza: (1) la arqueología de la costa es mucho mejor conocida que la serrana -puede ocasionalmente compensar la falta de datos etno-históricos; (2) en estos últimos años se ha hecho un esfuerzo nuevo para buscar fuentes escritas sobre las poblaciones costeñas (Murra 1972:444).

Desafortunadamente, esta propuesta del Tercer Caso de Verticalidad, referido a etnias pequeñas con núcleos en la costa que mantenían islas de explotación directa en el interior de los valles, no prosperó en ninguno de los dos sentidos. La arqueología costera en los Andes no ha documentado casos específicos de verticalidad y las interpretaciones de las fuentes escritas no han evaluado si los grupos costeros funcionaron bajo este modelo andino de organización social ${ }^{1}$. Por su parte, la arqueología de la costa de los Andes Centrales en cuyo valle de Chillón se originó el caso en comento, no se ha ocupado de contrastar específicamente esta temática salvo los estudios de Dillehay (1976, 1979, 1987), que se revisitan en este trabajo bajo la perspectiva de este y otros modelos o escenarios de interacción. Para los Valles Occidentales del área Centro Sur Andina (extremo sur de Perú y extremo norte de Chile), pese a la existencia de importante información arqueológica y bioantropológica, esta modalidad ha sido menos discutida y analizada (Lozada y Buikstra 2002; Julien 1985:186; Rostworowski 1986, 1989; Schiappacasse y Niemeyer 1989; Stanish 1992:167-168). Es interesante notar, sin embargo, que Lozada y Buikstra (2002) hablan de "verticalidad invertida" para el Osmore, mientras que para Arica se ha sugerido que población de tierras bajas habría dominado espacios de la sierra o precordillera (ca. 3.500-4.000 msm) en armonía con asentamientos de grupos serranos (Muñoz et al. 1987; Muñoz et al. 1997). En este contexto, recientemente hemos propuesto que los pescadores costeros de Arica manejaron enclaves agrícolas en el curso inferior del valle cercano a la desembocadura, bajo el Tercer Caso de Verticalidad (Santoro et al. 2009).

En contraste, el Segundo Caso correspondiente a grupos altiplánicos que habrían colonizado espacios en los valles costeros a varios días de distancia de núcleos en el altiplano circum Titicaca ha sido explícitamente aplicado para interpretar las existencia de rasgos altiplánicos en las tierras bajas (Covey 2000; Durston e Hidalgo 1997; Dillehay et al. 2006; Hidalgo y Focacci 1986; Llagostera 1976, 2010; Muñoz et al. 1987; Muñoz et al. 1997; Pärssinen y Siiriäinen 1997; Pease 1985; Schiappacasse et al. 1989; Schiappacasse y Niemeyer 1989; Santoro 1995; Stanish 1989)2.

En particular para los Valles Occidentales, los estudios etnohistóricos, a diferencia de la arqueología, se han preocupado con mayor detalle de los sistemas de organización política y económica de las sociedades de la costa y de los valles, lo que ha permitido distinguir una dinámica interacción entre grupos distintos de la costa, valle, sierra y altiplano (Durston e Hidalgo 1997). 
Se agregan, además, los influyentes planteamientos y descubrimientos de María Rostworowski quien propuso como alternativa a la verticalidad un modelo de especialización económica, el comercio de corta y larga distancia, así como la complementariedad entre etnias de pescadores y agricultores (Rostworowski 1973, 1981; 1989). Estas propuestas han sido retomadas por María Cecilia Lozada y colaboradores (Lozada et al. 2009).

En este artículo se contrastan datos arqueológicos del sector chaupiyunga del valle de Lluta complementados con información etnohistórica y bioantropológica de los Valles Occidentales para los períodos Intermedio Tardío y Tardío (ca. 1.0001.530 d.C.), con el objeto de discutir los posibles mecanismos de organización socioeconómica e interacción social que expliquen la variabilidad observada en la cultura material. Paralelamente se revisitan la arqueología y etnohistoria del valle de Chillón, cuya documentación sirvió de base a Murra para definir el Tercer Caso de Verticalidad con miras a verificar la posible existencia de patrones pan-andinos de interacción (Figura 1).

Nos centramos en el chaupiyunga, una etnocategoría geográfica bien reconocida en las fuentes coloniales de los Andes Centrales y Centro Sur (Rostworowski 1989:24, 246; ver también Craig 1985; Dillehay 1987:418; Santoro et al. 2009)3). En el valle de Lluta, el chaupiyunga es un punto intermedio y de conexión entre el valle costero y la sierra, entre los 700/900 y los $2.000 \mathrm{msm}$. Su clima cálido y seco la mayor parte del año, alejado de la influencia de las neblinas costeras, permite tener ciclos agrícolas alternativos a los del valle bajo con buenas condiciones para el cultivo de coca.

Por otro lado, en el chaupiyunga se identifica una mezcla de componentes culturales de la sierra, altiplano, Inka y de tierras bajas o Cultura Arica, esta última definida principalmente a partir de restos materiales como cerámica y textiles (Espoueys et al. 1995; Horta y Agüero 2009; Muñoz 1987; Schiappacasse et al. 1989; Santoro et al. 2004). Tanto la Cultura Arica, así como los otros componentes culturales interactuantes, no son entendidos aquí como "culturas arqueológicas" en el sentido dado por la arqueología histórico-cultural. Por el contrario, se estima que corresponden a la producción de un conjunto de artefactos estilisticamente similares, producción que resulta tanto de un proceso de enculturación

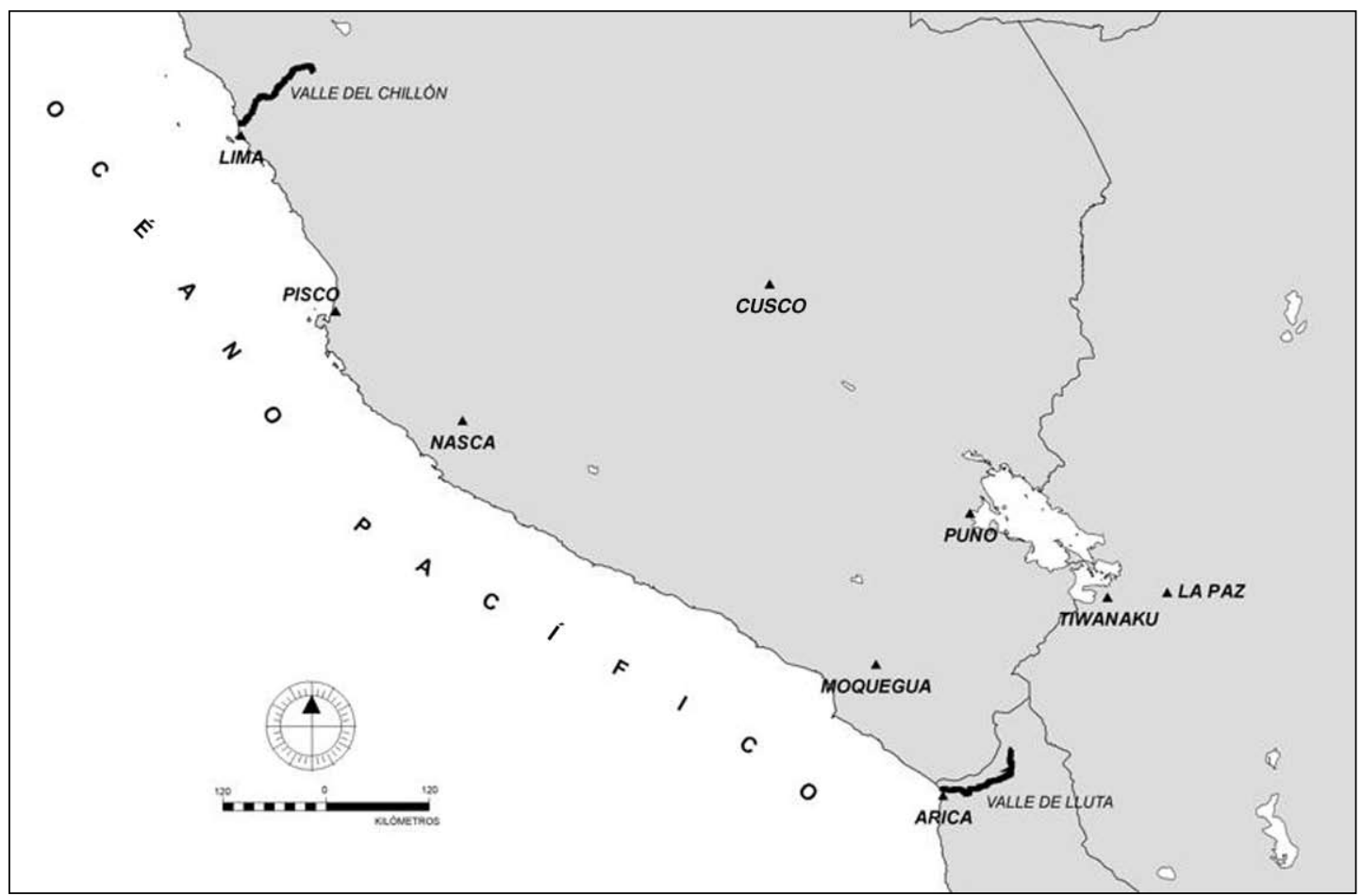

Figura 1. Andes Centrales y los Andes Centro Sur, con la ubicación de los valles de Chillón y Lluta. Central and South Central Andes and the Chillón and Lluta valleys. 
pasiva como de la conformación activa de identidades sociales. Estos referentes culturales remiten, directa o indirectamente, a contenidos sociales, políticos, ideológicos y económicos compartidos (Romero 2005).

Por otro lado, los datos arqueológicos disponibles no reflejan la estratificación sociopolítica de los señoríos de la cuenca del Titicaca, ni tampoco los niveles de jerarquización y poder corporativo de las sociedades segmentarias de los Andes Circumpuneños contemporáneas (Nielsen 2006a, 2006b). Sostenemos, más bien, que las tierras bajas de los Valles Occidentales congregaron a sociedades segmentarias o de rango (Santoro et al. 2004; Schiappacasse et al. 1989), es decir, pequeños grupos de descendencia independientes, carentes de estructuras políticas y económicas supralocales, con bajos niveles de centralización política y jerarquías sociales y caracterizados por continuos procesos de fisión y fusión basados en patrones de cohesión y oposición (Barnard y Spencer 1996; Evans-Pritchard 1960; Sahlins 1961). En consecuencia, pudieron llegar a formar amplias agregaciones de población sobre vastos territorios, fundados en la simple adscripción o en lazos de parentesco, compartiendo principios políticos, ideológicos y económicos comunes. Sociopolíticamente se habrían organizado mediante un modelo de poder reticular (sensu Feinman 2000) diferente a la organización política corporativa de las entidades altiplánicas (Romero 2005). El dominio de tipo reticular o excluyente habría sido sustentado por líderes prominentes que controlaron la producción y circulación de bienes de prestigio (tales como cerámicas y textiles de gran calidad) a favor de la legitimación del distanciamiento social de un linaje o grupos de linajes que disputaban permanentemente el poder. Este escenario de fragmentación política concuerda con el tamaño de los asentamientos en los valles bajos cuyas áreas domésticas no sobrepasan las 2 a 3 há. En este contexto, la cultura material característica y relativamente uniforme (Uribe 1995, 1999, 2000) que se extiende desde la costa hasta el chaupiyun$g a$, en el extremo sur de Perú y extremo norte de Chile, conformaría una especie de micro-horizonte cultural que se desenvolvió por este amplio espacio sin la intervención de una estructura política suprarregional, sino por efecto de la interacción de grupos segmentarios articulados por políticas reticulares.

\section{El Archipiélago Vertical: Dimensiones Económicas, Políticas y Demográficas}

Este modelo, basado en la distribución diferencial de recursos en los Andes producto de la gradiente altitudinal, consiste básicamente en un mecanismo de organización económica mediante el cual una comunidad accede directamente a distintos pisos ecológicos por medio del envío de colonias permanentes que conservan sus derechos en su núcleos de origen. Este modelo, sin embargo, con sus variantes empíricas y teóricas, no sólo da cuenta de aspectos económicos de las sociedades andinas, sino también de sus dimensiones políticas y demográficas.

La esfera política del modelo implica autonomía regulada, en la medida que la base central de la comunidad controla sus colonias residentes en zonas distantes, y los colonos mantienen sus derechos políticos en sus núcleos, una condición sine qua non que define al modelo según Murra. Además, estas colonias no siempre se movieron hacia territorios vacíos, consecuentemente entraron en conflicto o llevaron a cabo acuerdos de corresidencia con grupos locales y otros foráneos interesados en ocupar y explotar la misma zona de recursos. Las consideraciones políticas del modelo en el envío y mantenimiento de colonias a larga distancia, así como el retorno de la producción al núcleo y su consiguiente redistribución, implican niveles de organización política más centralizados, mayor complejidad logística y redes de interacción social favorables. No obstante, esta organización económica a menor escala se basó fuertemente en el parentesco. Este aspecto del modelo de Murra no ha recibido tanta atención como la dimensión económica y demográfica, lo que demanda de mayor investigación, no sólo acerca de la fragmentación espacial y social de las relaciones de parentesco en las colonias, sino también en cuanto a las implicaciones políticas de competir o colaborar con grupos distintos para acceder a diferentes zonas ecológicas. Como resultado, la producción y tráfico de bienes y recursos en territorios distantes por parte de diferentes grupos debió crear múltiples estrategias y arreglos político-económicos que incluyó desde relaciones coercitivas a voluntarias.

$\mathrm{El}$ aspecto económico del modelo supone que el envío de colonias a zonas ecológicas distantes, localizadas a elevaciones diferentes, permite a 
las comunidades expansivas tener acceso y control de una variedad de recursos, consiguiendo así una autarquía económica. Las implicancias demográficas de esta expansión son obvias: las comunidades en las colonias se fisionaron o fusionaron o cambiaron de adscripción, transgrediendo las estructuras sociales que se derivan del núcleo o marka central para controlar recursos en zonas alejadas. Esta mezcla pudo ocurrir tanto a nivel de sociedades que manejaban el sistema vertical más centralizadamente como a nivel de grupos y redes de parentesco independientes, todo con miras a concretar el "ideal" de complementación ecológica.

\section{El Caso de Quivi, Valle de Chillón, Costa Central del Perú y el Tercer Caso de Verticalidad}

Murra discutió el Tercer Caso con base en información del período Colonial temprano (siglo XVI) sobre los Collique, grupo con asientos principales en la costa central de Perú que sin embargo accedieron a recursos a unos $50 \mathrm{~km}$ de la costa y a $1.000 \mathrm{~m}$ de altitud, en pleno valle de Chillón, al sur de Lima (Murra 1972:445 y ss). Estas tierras, identificadas como los cocales de Quivi, estaban emplazadas en el denominado ambiente chaupiyunga. El acceso a los cocales no habría estado exento de problemas, en la medida que este territorio fue, también, objeto de interés y uso por parte de otros grupos locales y otros provenientes de la sierra. En efecto, en el litigio de 1559 se documenta la disputa de los cocales de Quivi por parte de cuatro grupos distintos: el grupo costeño Collique, el grupo yunga de Quivi y dos etnias serranas, los de Canta y una división de los Yauyos, los Chacalla. Los testimonios de estos grupos en el litigio judicial coinciden en reconocer que antes del Inka, los dominios de Collicapa, señor principal de los Collique, alcanzaban la costa y Quivi. Esta localidad, en tanto, era regida por Chaumecaxa, señor en sí de origen yunga que tributaba a Collicapa. Antes de la conquista Inka no existieron controles territoriales excluyentes, por el contrario, se fijaban deslindes de tierra para usufructo de todas las partes.

[...] yndios de Chacalla [...] se confederaron con los yndios que a la dicha sazón avia en las dichas tierras de Quivi que eran yndios yungas [...] e se concertaron con los... de Chacalla que no los conquistasen syno que se mojonasen las tierras e que lo que avia de ser de cada vno e que no rreñyesen e anzy dize que les señalaron que las... tierras Quybi vn mojon... e que alli los... yndios yauyos habian hecho su población e que las avian tenydo y poseydo bien por dos vidas hasta que paso y vino Topa Ynga Yupangue (Murra 1972:447).

De los testimonios de los grupos litigantes, Murra (1972:449) sugiere: (1) la existencia de un señorío costeño antes del Inka, con su núcleo en Collique y regido por Collicapa; (2) este señorío costeño accedía a recursos en Quivi, a $50 \mathrm{~km}$ del núcleo valle arriba, un espacio adecuado para el cultivo de coca, algodón, ají y fruta; y (3) la administración de estos territorios requirió de protección militar, dado que eran objeto de presión serrana.

No obstante, Murra (1972:445, 452) manifiesta incertidumbre respecto de si este ejemplo etnohistórico constituyó realmente un Tercer Caso de Verticalidad, "no en un plan de insistir que los archipiélagos existieron, sino buscando los límites del modelo" (Murra 1972:445):
¿Es este un caso más de "archipiélago vertical"? Las tres proposiciones lo sugie- ren pero no faltan dudas. Los informantes estaban de acuerdo en que los de Quivi eran "yungas" viviendo por encima de los mil metros, pero no sabemos todavía si eran asentamientos periféricos de gente enviada desde Collique quienes seguían manteniendo su participación social y dere- chos en la costa -condición que me parece indispensable para definir los archipiélagos (Murra 1976:449; énfasis original).

Posteriormente, en la revisión del modelo, Murra (1976) focalizó su atención en los reinos lacustres redefiniendo el modelo como "patrones andinos de poblamiento, de explotación simultánea de varios pisos ecológicos por una misma población" (Murra 1976:144; énfasis original). En esta reconsideración, Murra apenas se refiere a la verticalidad costera, reafirmando sus dudas respecto a la existencia del Tercer Caso planteadas en su artículo de 1972. 


\section{Discusión del caso de Quivi}

Está claro en la Probanza de Canta que en algún momento previo a la invasión Inka al valle del Chillón, el señorío costero Collique tuvo acceso a tierras y recursos del sector chaupiyunga en Quivi, y que más tarde los de Quivi pagaron tributo a los primeros. El problema es que en ninguna parte de dicha Probanza se menciona explícitamente que los Collique enviaron gente a vivir a Quivi que pudiera ser interpretado como colonias permanentes, ya sea para proteger sus intereses económicos, proteger a la gente de Quivi de los invasores o proveer trabajo extra en los cocales y otros cultivos. Como Murra lo notó, no queda claro si el caso de Quivi representa verticalidad.

La relación de dominación y subordinación entre Collique y Quivi, respectivamente, bajo la perspectiva arqueológica de los estudios de Dillehay (1976, 1979, 1987), puede representar varios escenarios económicos y políticos diferentes que incluyeron, entre otros, verticalidad, conflictos, varios arreglos para compartir recursos, derechos y control de aguas, matrimonios, alianzas y acuerdos de intercambio.

\section{Confrontación de datos etnohistóricos y arqueológicos para el caso de Quivi}

El caso del Chillón presenta un interesante dilema entre las perspectivas arqueológicas y etnohistóricas en el estudio de la verticalidad. Mientras las fuentes escritas han sido interpretadas como posible caso de verticalidad, los datos arqueológicos son más ambivalentes en la aplicación del modelo de verticalidad en el valle y perciben diferentes estrategias político-económicas que operaron secuencial o simultáneamente entre los grupos de la costa, chaupiyunga y los Andes durante los períodos en debate. ¿Qué datos son más correctos en este caso? Ambos son posiblemente correctos por varias razones.

Los datos etnohistóricos dan cuenta de un período más bien corto de tiempo respecto de la tenencia de tierra y las relaciones inter-grupales entre los líderes Quivi y Collique. Se refieren al período inmediatamente anterior a la conquista Inka. Varios residentes del valle fueron entrevistados por los españoles, según se señala en la Probanza de Canta, para documentar quiénes eran los propietarios del área de Quivi y cuáles eran las relaciones de poder entre los caciques en la época previa al arribo Inka. Es importante reconocer que la Probanza se refiere sólo al período Inka cuando el así llamado cacique Collicapa tenía acceso a tierras de Quivi, lo que posiblemente fue sólo por dos o tres décadas.

Por otro lado, los datos materiales de la arqueología del período Tardío o Inka (ca. 1.3001.520 d.C. $)^{4}$ en el valle del Chillón, muestran sitios fortificados que indican conflictos intergrupales, bocatomas relacionadas con derechos y control de aguas a nivel inter-valle y asentamientos corresidenciales caracterizados por arquitectura, tejidos, cerámica y productos alimentarios costeros y altoandinos (Dillehay 1976, 1979, 1987). Durante este período de doscientos a trescientos años, la arqueología muestra en el valle diferentes tipos de relaciones de dominación y subordinación, igualitarias y no igualitarias, entre grupos de la costa, chaupiyunga y altoandinos y no simplemente entre los líderes Collique y Quivi.

Varios sitios arqueológicos en el chaupiyun$g a$, incluyendo Huancayo Alto, Santa Rosa de Quivi, Macas, entre otros, evidencian corresidencia de altoandinos y costeros con épocas de relaciones pacíficas. Más interesante aún es que el sitio Quivi se caracteriza por la presencia de una amplia variedad de estilos cerámicos costeros, chaupiyunga y altoandinos, lo que sugiere que el sitio fue ocupado, visitado y/o liderado por diferentes grupos costeros y de tierras altas durante este período. Desafortunadamente, gran parte de la arquitectura de Quivi ha sido destruida por actividad moderna, por lo que poco se puede señalar respecto de la funcionalidad, cronología, y secuencia de los arreglos de corresidencias entre estos grupos. Consecuentemente, no podemos saber si la corresidencia o co-acceso, como lo indica la mezcla de estilos cerámicos, representa episodios secuenciales de: (1) dominio costero, chaupiyunga y altoandino en territorios de Quivi; o (2) colonias costeras o altoandinas compartiendo tierras en Quivi a través de asociaciones basadas en modelos de verticalidad, alianzas matrimoniales $\mathrm{u}$ otros arreglos. Cualquiera de estos escenarios produciría una mezcla de arquitectura, cerámica y otros materiales, como se observa en Quivi y, como veremos a continuación, también en Lluta. 


\section{El Tercer Caso de Verticalidad: EI Valle de Lluta, Extremo Norte de Chile}

Se ha estimado que, a diferencia de los Andes Centrales, las poblaciones de los Valles Occidentales, Andes Centro Sur, no tuvieron sistemas de organización política altamente centralizados que les permitieran tener control de territorios a nivel supralocal. En particular, Lumbreras (1981:261) definió a estas poblaciones como "pescadores primitivos, que al parecer estaban sujetos a un trato servil similar al de los uros del lago Titicaca". Respecto de las poblaciones altiplánicas que habrían colonizado la zona en época post-Tiwanaku, Rostworowski $(1986,1989)$ señaló que el tamaño de los grupos de tierras bajas habría sido insuficiente para hacer frente a las presiones de los grupos altiplánicos. Murra (1976:145) indicó que "es obvio que los reinos lacustres del Titicaca pudieron extender "islas" hacia el Pacífico ya que no hubo ni en la costa, ni en los territorios intermedios ningún núcleo de poder de envergadura" que les hiciera frente. Así, para los Valles Occidentales, el Segundo Caso de Verticalidad se ha perfilado como una de las estructuras que organizó las relaciones entre altiplánicos -con los Lupaqa como el ejemplo clásico-y los grupos de pisos ecológicos más bajos (Llagostera 1976, 2010; Murra 1972).

\section{Información etnohistórica}

A pesar de lo fragmentario de la información etnohistórica del período Colonial temprano (segunda mitad del siglo XVI), se ha logrado establecer la existencia de dos grupos económica, política y tal vez lingüísticamente diferenciados: pescadores, con asientos principales a lo largo de la costa y agricultores alojados en los valles (Hidalgo 2009; Julien 1985; Rostworowski 1981, 1986). Rostworowski (1981, 1986) señala que se habrían establecido relaciones asimétricas de intercambios y de subordinación de los pescadores respecto de los agricultores. Cada uno de los grupos era endogámico y mantenía sus propias autoridades políticas (ver sin embargo Lozada y Buikstra 2002).

De acuerdo a Julien (1985:206-207), en los valles bajos entre Majes y Tarapacá, los grupos de pescadores eran unidades independientes de los agricultores del valle y posiblemente mantenían cultivos, especialmente maíz, en las cabeceras de los valles, donde además se congregaban poblaciones de las zonas altoandinas.
Hidalgo (1982) ha discutido la diferenciación entre pescadores y agricultores, así como las contradicciones entre fuentes etnohistóricas y arqueológicas. Agrega que los pescadores mantuvieron enclaves agrícolas en zonas de inundación cercanas a las desembocaduras de los valles, mientras que los agricultores mantuvieron sus propios enclaves costeros, lo que habría creado relaciones más dinámicas, igualitarias o de subordinación, que cambiaban de un grupo a otro (Hidalgo 1982, 2009; Hidalgo y Focacci 1986; ver una evaluación arqueológica en Schiappacasse y Niemeyer 1989, 2002). En el siglo XVII, pescadores camanchacas mantenían tierras de cultivo en Saucache, Azapa (5 a $7 \mathrm{~km}$ de la costa), donde a su vez se ubicaba el límite entre las tierras de los pescadores y los agricultores (Hidalgo et al. 1997). Otros enclaves agrícolas de los pescadores se ubicaban más al interior de dicho valle: en Ocurica ( 7 a $12 \mathrm{~km}$ de la costa) y en las vertientes Media Luna y El Gallito (quebrada de Las Llocllas, 12 a $14 \mathrm{~km}$ de la costa) (Hidalgo 2004:459-466).

Específicamente para el valle de Lluta, documentos del siglo XVI sugieren la presencia de colonias Lupaqa, Caranga y Pacaje, lo que se ha interpretado como evidencia de verticalidad (Hidalgo y Focacci 1986; Murra 1972; Santoro et al. 1989). Documentos del siglo XVIII mencionan que gente de la cuenca superior del valle (sobre $3.000 \mathrm{msm}$ ) mantenía cultivos en el sector chaupiyunga (entre 1.000 y $1.200 \mathrm{msm}$ ): "Jente de Socoroma y Putre asiste la mayor parte del año en el dicho valle de Sora y Churiña donde tienen sus sementeras de mais y trigo" (Durston e Hidalgo 1997:265). Junto con la evidencia etnohistórica que sugiere control vertical en los Valles Occidentales, documentación del siglo XVI señala que los tacna tenían dominios en Codpa, varios kilómetros al sur de Arica, mientras que los tarapacá en Azapa y los huatacondo en Camarones (Hidalgo et al. 1997), lo que Murra (1972:444) definió como control longitudinal.

En síntesis, de los casos etnohistóricos reseñados se pueden extraer los siguientes puntos en común: (1) diferenciación entre pescadores y agricultores, al menos desde el punto de vista económico y territorial; (2) pescadores tenían acceso a tierras en el interior de los valles para cultivar, donde compartían con agricultores locales y agropastores altoandinos; y (3) relaciones de interacción y subordinación mutua alternante entre pescadores y agricultores. 


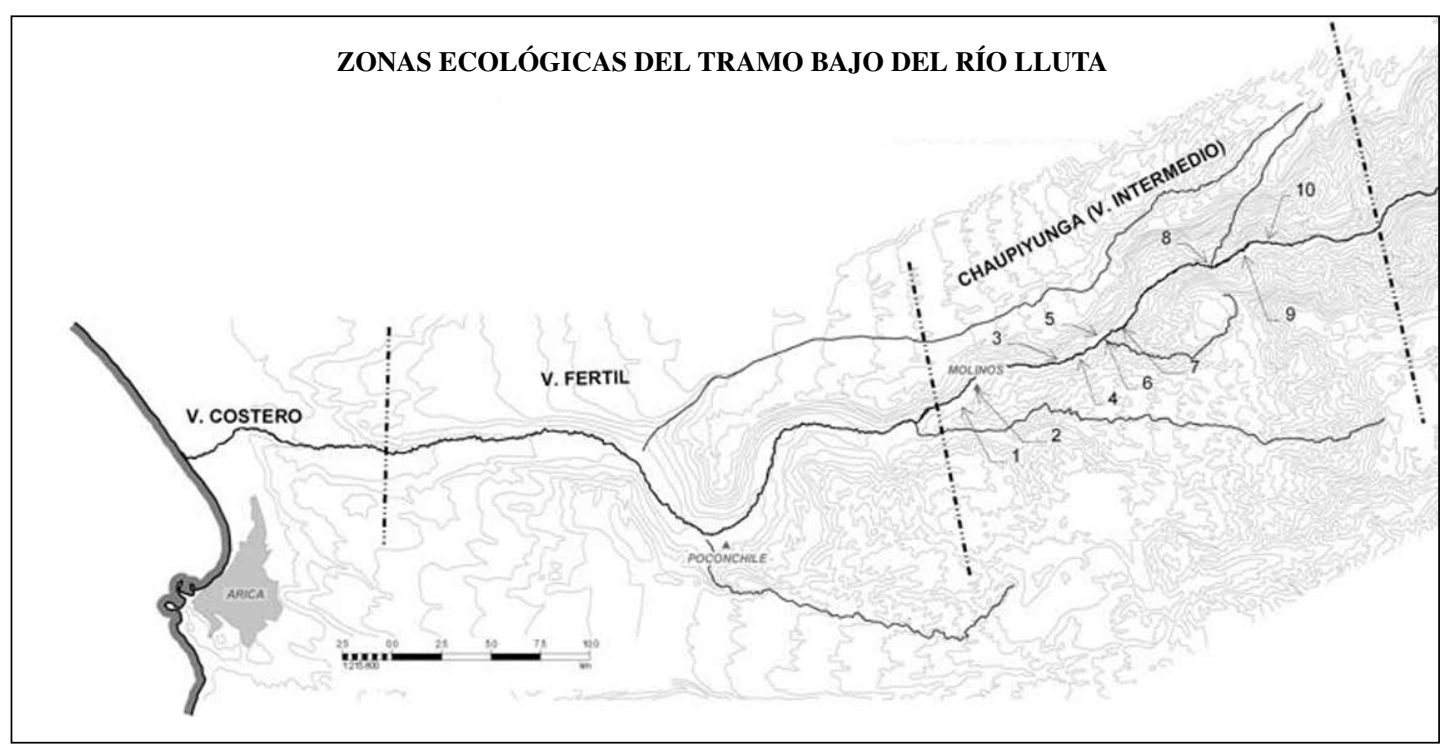

Figura 2. Subdivisiones ecológicas del Lluta y yacimientos arqueológicos del sector Chaupiyunga citados en el texto: 1: L1-42 Taypimarka; 2: Ll-44 Molinos Oeste y L1-43 Cruces de Molino; 3: L1-98 Marka Vilavila; 4: L1-41 Chapisca y L1-40 Intine; 5: L1-96 Sora Norte; 6: Ll-28 Chaquire; 7: L1-19 Sora Sur; 8: L1-21 Poblado Millune y L1-22 Millune Oeste; 9: L1-91 Arancha; 10: Ll-92 Vinto 1-2 y L1-92 Vinto 4.

Ecological subdivision of the Lluta Valley and the studied archaeological sites listed in the text: (1) Ll-42 Taypimarka; (2) Ll-44 Molinos Oeste and Ll-43 Cruces de Molino; 3: Ll-98 Marka Vilavila; (4) Ll-41 Chapisca and Ll-40 Intine; (5) Ll-96 Sora Norte; (6) Ll-28 Chaquire; (7) Ll-19 Sora Sur; (8) Ll-21 Poblado Millune and Ll-22 Millune Oeste; (9) Ll-91 Arancha; (10) Ll-92 Vinto 1-2 and Ll-92 Vinto 4.

\section{Información arqueológica en el sector chaupiyunga del valle de Lluta}

En el período Intermedio Tardío (ca. 1.0001.400 d.C.) y período Tardío o Inka (ca. 1.400-1.535 d.C.) se verifica una serie de sitios arqueológicos habitacionales, funerarios y de arte rupestre (Figura 2) ${ }^{5}$. De este conjunto se analizaron siete sitios habitacionales y funerarios, examinados en sus aspectos arquitectónico y de organización espacial $^{6}$, complementado con estudios iconográficos y espaciales de 11 sitios con arte rupestre (Valenzuela et al. 2004). Adicionalmente, se estudió la distribución de tipos de pastas (estándares) y decoración cerámica (grupos estilísticos) sobre una muestra de superficie obtenida en sitios habitacionales y funerarios. Estos análisis en conjunto dieron como resultado un heterogéneo escenario de coexistencia de diversos componentes culturales que se resumen a continuación (ver Romero 2005:41-43; Santoro et al. 2001; Santoro et al. 2009:90-92).

Componente cultural de tierras bajas o local: Caracterizado por la pasta estándar E-400 con la que se manufacturó gran parte de la cerámica decorada y no decorada del grupo estilístico Arica que incluye los clásicos estilos policromos San Miguel, Pocoma y Gentilar.

Componente cultural serrano: Se caracteriza por la pasta E-500 y el grupo estilístico Charcollo, que aparece con mayor frecuencia en la sierra. En contraste, esta pasta no fue usada para fabricar tiestos del grupo estilístico Arica.

Componente cultural altiplánico: Compuesto por la pasta E-220 y el grupo estilístico Negro sobre Rojo, integrado principalmente por el estilo Chilpe. Se consideran originarios del altiplano al suroeste del Titicaca, territorio de los Pacaje y Caranga.

Componente cultural Inka: Integra la pasta E-210 de origen altiplánico y el grupo estilístico Inka compuesto por los estilos Saxamar o Inka Pacaje.

Al igual que en el sector chaupiyunga del Chillón, en Lluta estos componentes se distribuyen heterogéneamente al interior de cada uno de los sitios estudiados. En el Intermedio Tardío se registra sólo el Patrón de Asentamiento I (PAI), en cuyos ámbitos domésticos y funerarios predominan las pastas serrana E-500 (47\%) y de tierras bajas 
E-400 (40\%). Las pastas altiplánicas E-210 y E-220 son minoritarias ( $4 \%$ y $5 \%$, respectivamente), así como la categoría otros estándares $(4 \%)$. En la cerámica decorada hay un predominio del grupo estilístico altiplánico Negro sobre Rojo (41\%) y del grupo estilístico Arica (30\%). Se agregan el grupo estilístico serrano Charcollo (7\%), Inka (7\%, considerado intrusivo en los sitios) y otra serie de fragmentos de estilos no identificados (15\%) (Santoro et al. 2009).

Para el período Tardío se registran el Patrón de Asentamiento II (PAII) y Patrón de Asentamiento III (PAIII), este último exclusivo del chaupiyunga. En los sectores domésticos, las pastas de tierras bajas E-400 (32\% y $37 \%$ respectivamente) compiten con las pastas serranas E-500 (30\% y $40 \%$ respectivamente) y con las pastas altiplánicas en conjunto E-210 y E-220 (31\% y 19\% respectivamente) y otros estándares (7\% y 4\%, respectivamente). En contraste, las áreas funerarias asociadas al PAIII ${ }^{7}$ presentan una alta incidencia de pastas de tierras bajas E-400 (35\%) y E-221 (35\%), superando notoriamente a las pastas serranas E-500 (19\%), altiplánicas E-210 y E-220 (3\% y 6\% respectivamente) y otros estándares (3\%).

En el período Tardío la cerámica decorada en sitios PAII muestra un predominio de estilos Inka (40\%) seguido de los estilos Arica (32\%), mientras que el grupo estilístico altiplánico Negro sobre Rojo, el serrano Charcollo y otros estilos presentan baja frecuencia (17\%, 3\% y $8 \%$, respectivamente). En contraste, en los ámbitos domésticos de los sitios PAIII hay un notorio dominio de los estilos Arica (51\%), seguidos de los estilos Negro sobre Rojo (29\%), Inka (7\%), Charcollo (6\%) y otros estilos (7\%). En los ámbitos funerarios de PAIII el grupo estilístico Arica es altamente mayoritario (84\%), con baja representación de los grupos estilísticos Negro sobre Rojo (8\%), Charcollo (4\%), Inka (1\%) y otros estilos (3\%).

El arte rupestre de los períodos Intermedio Tardío y Tardío evidencia igualmente diversidad, en términos tecnológicos, iconográficos, espaciales $\mathrm{y}$ funcionales, lo que contrasta con la uniformidad del arte rupestre de los sectores costero y fértil (Valenzuela 2004; Valenzuela et al. 2006). Destaca un arte rupestre doméstico, típico del chaupiyunga, caracterizado por una iconografía propia compuesta por horadaciones circulares y líneas sinuosas, posiblemente relacionada con la ritualidad agrícola (Valenzuela et al. 2004). Paralelamente, se identifica un arte rupestre de tráfico que marca lugares de acceso de las caravanas al interior del valle mediante rutas secundarias que lo conectaban con rutas interregionales tierras altas-costa. Este tipo de sitios, caracterizado iconográficamente por caravanas de llamas, no sólo materializa una de las vías a través de las cuales ingresaron los bienes y recursos importados presentes en el registro arqueológico de este sector, como por ejemplo la cerámica, sino que también sugiere que las poblaciones del chaupiyunga participaron como agentes activos en las redes de intercambio (Valenzuela et al. 2009).

Análisis en proceso de recientes excavaciones arqueológicas en sitios habitacionales del chaupiyunga (Poblado Millune, Sora Sur, Vinto 1-2, Arancha) muestran la relación con las tierras altas y la costa a través de materiales tales como huesos de camélidos, cerámica, obsidiana y conchas del Pacífico. Estos ítems, junto con la evidencia del arte rupestre y la cerámica importada, confirman que el sector chaupiyunga participaba de una esfera de interacción que incluía desde la costa hasta el altiplano, al igual que en el Chillón.

Resumiendo la información arqueológica, el sector chaupiyunga de Lluta durante el período Intermedio Tardío aparece como un espacio en el que se integran diferentes referentes culturales: de tierras bajas o locales, serranos y altiplánicos (Santoro et al. 2009). Se observa también que no hay una predominancia clara ni de los componentes culturales locales ni de los componentes serranos y altiplánicos, tanto en los ambientes domésticos como funerarios. Esta situación marca una diferencia con respecto a los sectores costero y fértil ubicados en pisos altitudinales más bajos donde hay una predominancia del componente de tierras bajas (Santoro et al. 2009). En particular, la cerámica Negro sobre Rojo está ausente en el sector costero y presenta baja frecuencia en el sector fértil (Romero et al. 2000; Santoro et al. 2009).

En contraste, durante el período Tardío los referentes culturales de tierras bajas, de tierras altas (serrano, altiplánico) e Inka se comportan de manera diferencial en contextos domésticos y funerarios, así como también varían según el tipo de asentamiento. Las pastas altiplánicas y serranas predominan en ambos tipos de asentamientos (PAII y PAIII). En cambio, los estilos decorativos importados (especialmente Inka) predominan sólo en los asentamientos PAII, mientras que en los asentamientos PAIII 
dominan ampliamente los estilos locales Arica. En los contextos funerarios, por otra parte, los tipos de pasta y estilos decorativos de tierras bajas o locales son mayoritarios. En cambio, la población de fuerte raíz local del sector costero se mantiene independiente del Estado Inka, mientras que en el sector fértil se verifica una intervención más directa del Tawantinsuyu (Santoro et al. 2009).

\section{Discusión valle de Lluta}

Las interpretaciones etnohistóricas han propuesto la coexistiencia de grupos costeros, de valle y de tierras altas en los Valles Occidentales en tiempos coloniales tempranos, que se ha explicado a través del Segundo Caso de Verticalidad (Hidalgo 2009; Hidalgo et al. 1988; Murra 1972) al que se ha definido una variante conocida como verticalidad escalonada (Durston e Hidalgo 1997). Como una manera de explicar la presencia de componentes culturales de tierras altas en los valles bajos la arqueología ha extendido la profundidad cronológica del Segundo Caso hasta tiempos prehispánicos tardíos (Hidalgo y Focacci 1986; Llagostera 1976, 2010; Muñoz et al. 1987; Muñoz y Santos 2000; Schiappacasse et al. 1989; Schiappacasse y Niemeyer 1989; Santoro 1995; Stanish 1992), así como también la variante verticalidad escalonada (Santoro et al. 2009). Por otra parte, el tráfico caravanero y el intercambio se han señalado como mecanismos alternativos de interacción social (Núñez y Dillehay 1995; Rostworowski 1986).

Las investigaciones bioantropológicas de poblaciones del señorío costero Chiribaya (sur de Perú) del Intermedio Tardío no muestran cambios biológicos significativos provocados por el ingreso de contingentes altiplánicos, lo que significa que procesos de colonización a través de la verticalidad u otros mecanismos migracionales desde el altiplano no tendrían sustento bioantropológico (Lozada y Buikstra 2002; Sutter y Mertz 2004). Consecuentemente, la variabilidad observada en el registro arqueológico, particularmente en la zona chaupiyunga del valle de Osmore (Lozada y Buikstra 2002), respondería a otros mecanismos de interacción que no involucraron necesariamente el ingreso y asentamiento de población externa. Sin embargo, estudios sobre poblaciones de las tierras bajas de Arica (valle de Azapa) muestran miscegenación discreta con poblaciones altiplánicas, sin constituir procesos masivos de inmigración (Rothhammer y Cocilovo
2008; Rothhammer y Santoro 2001). Este caso implicaría no sólo el traslado de bienes y recursos, sino también pequeños flujos de población que se integraron a las poblaciones de tierras bajas.

Como en el caso del valle de Chillón, cada uno de los sitios arqueológicos del sector chaupiyunga de Lluta muestra la integración de cerámica y otros materiales de origen altiplánico, serrano y de tierras bajas. Esta evidencia no se presenta en la forma de asentamientos coloniales tipo "islas" étnicas, como sugiere el modelo de verticalidad donde se debería esperar agrupaciones de rasgos cerámicos, arquitectónicos, funerarios y de otros elementos culturales, diferenciados en cada uno de los asentamientos. Por el contrario, cada uno de ellos contiene una mezcla de estos rasgos que no forman conjuntos diferenciados entre sí. Este panorama arqueológico recuerda el patrón de "revoltijo" o de "cabos sueltos" observado por Platt (2010) en la década de 1970, en la zona valles interandinos, o intermontanos (ca. $2.500 \mathrm{msm}$ ) de ocupación multiétnica de los Macha del norte de Potosí, Bolivia.

A diferencia del valle de Chillón, los sitios del chaupiyunga de Lluta no fueron fortificados, lo que significa que si existieron conflictos, éstos se enfrentaron de otra manera. Esto se relaciona, tal vez, con la escala de las operaciones productivas en el valle de Lluta, donde existían pequeños espacios y volúmenes de recursos, grupos poblacionales no muy grandes, bajos niveles de inversión en infraestructura doméstica y agrícola, lo que contrasta con la escala mucho mayor del Chillón. Esto significó, por ejemplo, que el Inka estableciera un centro administrativo en el Chillón, no así en el chaupiyunga del Lluta. Por otro lado, a diferencia del caso del valle de Chillón, en Lluta la documentación etnohistórica es mucho más fragmentaria y general y, salvo contadas excepciones, no se refiere específicamente a este valle, de modo que la interpretación de los mecanismos de interacción depende más de los análisis arqueológicos y bioantropológicos.

\section{Discusión y Conclusiones}

De los casos etnohistóricos y arqueológicos del Chillón, en la costa central de Perú, y del Lluta, en la costa del extremo norte de Chile, se deducen una serie de situaciones históricas relevantes a la discusión sobre los mecanismos de interacción entre grupos de costa, valle, sierra y altiplano durante la época tardía de la prehistoria (ca. 1.000-1.530 d.C.). 
En el chaupiyunga tanto del Chillón como del Lluta se verifican dos fenómenos importantes: (a) la integración de una variedad de componentes culturales: de tierras bajas, de la sierra, del altiplano e Inkas; y (b) comparativamente respecto de los sectores más bajos, el sector chaupiyunga registra la mayor incidencia de componentes cerámicos de tierras altas.

En el caso del valle de Chillón, aunque el control vertical del chaupiyunga por parte de los Collique en Quivi pudo haber funcionado inmediatamente antes del arribo del Inka, el patrón arqueológico dominante más bien parece ser reflejo de un mosaico de estrategias intergrupales cambiantes, que incluyó la corresidencia, el co-acceso a recursos y la verticalidad. Por otro lado, tanto los estudios arqueológicos como etnohistóricos concuerdan en que Quivi fue una base central o un puerto de entrada a través del cual diferentes grupos negociaron sus relaciones de poder. Aunque las poblaciones radicadas en Quivi y en otras localidades chaupiyunga no tuvieron una base agrícola y demográfica de suficiente envergadura como para gobernar el valle completo, poseyeron una importante posición geopolítica que les proveyó de ciertos poderes y derechos que no eran inherentes a los grupos costeros o altoandinos.

La relación descrita entre los Collique y los Quivi en la Probanza de Canta representa personas específicas, grupos y eventos dentro de un período relativamente corto. Esto no significa necesariamente que Collicapa haya recibido tributo desde Quivi o que haya tenido tierras en Quivi durante todo el período Intermedio Tardío y el período Inka temprano. Si este fuera el caso, si Collique fue tan importante en el valle al momento de la conquista Inka, ¿por qué el principal centro administrativo Inka fue ubicado en Huancayo Alto, en el chaupiyunga $y$ en otras localidades con dominio visual del valle y no en el curso inferior, asiento de los Collique (Dillehay 1987)?

Uno de los escenarios alternativos podría corresponder a arreglos político-económicos entre Quivi y Collique, expresados en simples intercambios de productos, como lo señala Rostworowski (1972, 1973, 1989). Otra posibilidad sería que la gente de Quivi buscó protección militar del señorío Collique, a cambio del acceso por parte de los Collique a los cocales y otros recursos del chaupiyunga. Hay que recordar que los de Quivi eran amenazados por vecinos de tierras altas como los de Canta, quienes tenían conflicto con los Collique y los Yauyo de las tierras altas de Huarochirí hacia el suroeste. Este escenario no implica necesariamente que los señores Collique tenían colonias en Quivi. Un tercer escenario se relaciona con los derechos de agua entre Quivi y Collique, donde los primeros protegían las bocatomas de los canales que irrigaban los campos de cultivo Collique en el valle medio y bajo. ¿Ocurrió esto a cambio de la protección contra los grupos de tierras altas renegados? Una cuarta alternativa sería el intercambio de esposas o esposos en uniones matrimoniales entre estos grupos, a partir de cuyos lazos de parentesco se estableció la producción y traslado de productos.

Por su parte, el escenario político para los Valles Occidentales, entre Arequipa y Tarapacá, antes de la colonización Inka y europea, conformado a partir de fragmentos dispersos de información etnohistórica, muestra que los grupos locales pescadores y agricultores no estaban constreñidos exclusivamente a la costa y los valles respectivamente. Se ha podido establecer que los pescadores camanchacas controlaban enclaves de producción agrícola en territorios hasta 10 y más kilómetros del litoral, como Saucache, Ocurica y las vertientes de Media Luna y El Gallito, en el valle de Azapa, al sur del valle de Lluta. Dado que los pescadores se ubicaban en territorios del valle más bien marginales desde el punto de vista agrícola, es posible que dichos campos de cultivo fueran producidos directamente por los pescadores sin entrar en conflictos con los agricultores, quienes, a su vez, se ubicaban más al interior del valle donde las tierras son mejor drenadas, menos salobres, más amplias y con acceso a vertientes de agua más dulce que la del propio río Lluta. Amparados en este marco etnohistórico y el complemento de los datos arqueológicos, mantenemos la conclusión previa para el valle de Lluta que los grupos de la costa pudieron manejar sus enclaves agrícolas cercanos a la desembocadura a través del Tercer Caso de Verticalidad (Santoro et al. 2009).

Los agricultores mantuvieron enclaves en ambientes de costa y valle incluyendo el sector chaupiyunga a más de $70 \mathrm{~km}$ del litoral. También accedieron a recursos en pisos ecológicos similares, bajo un régimen de control horizontal o de intervalles; como los tacna que tenían dominios en Codpa, los tarapacá en Azapa y los huatacondo en Camarones, al menos durante el período Colonial temprano (Hidalgo y Durston 1998; Hidalgo et al. 1997). 
En particular para el chaupiyunga del valle de Lluta, como en el Chillón, consideramos que el panorama arqueológico refleja la operación de más de un mecanismo de complementariedad e interacción.

En efecto, el chaupiyunga presenta condiciones ideales para la interacción multiétnica, puesto que su explotación, ya sea desde la sierra o de la costa requiere del mantenimiento de asentamientos islas permanentes. El chaupiyunga queda entre 20 a $30 \mathrm{~km}$ del sector bajo del valle, entre 60 a $70 \mathrm{~km}$ de la costa, 30 o más km de la sierra y entre 60 a $70 \mathrm{~km}$ del altiplano, lo que imposibilita la conmutación diaria entre este enclave y sus núcleos centrales hacia los costa o la sierra, típico del patrón de micro-verticalidad. Consecuentemente, una manera de explicar la variabilidad cultural del chaupiyunga en el Lluta sería a través del Tercer Caso de Verticalidad. Lo que significaría que individuos del valle bajo se asentaron en dicho lugar para actividades productivas, compartiendo los mismos espacios domésticos con individuos de la sierra y altiplano. Los contingentes de la sierra y posiblemente del altiplano habrían operado bajo el Segundo Caso de Verticalidad o de verticalidad escalonada. Ninguno de estos grupos, sin embargo, estableció campamentos "islas" independientes; por el contrario, crearon un espacio multiétnico mezclado en los ámbitos domésticos.

Aunque la verticalidad aparece como un buen mecanismo para explicar la variabilidad arqueológica del chaupiyunga del valle de Lluta, no se puede descartar la posibilidad que otros mecanismos hayan operado, los cuales en algunos casos implican igualmente la instalación de poblaciones foráneas. En este contexto, un primer escenario sería a través de redes de parentesco real o ficticio, expresado por el intercambio de esposas o esposos o la inmigración temporal o permanente de individuos o grupos muy pequeños para apoyar labores productivas de parientes. En este sistema, el intercambio entre grupos de tierras bajas, serranos y altiplánicos habría creado la heterogeneidad cultural del chaupiyunga.

Un segundo escenario, referido especialmente a las poblaciones de los valles, tiene que ver con la ausencia de sitios fortificados o defensivos en el Lluta, señal de conflictos intergrupales explícitos. A ello se suma bajos niveles de traumas corporales en general en los valles bajos durante la prehistoria tardía, que contrasta con los períodos más tempranos
(Arcaico y Formativo) que muestran alta incidencia de traumas por violencia interpersonal (Standen y Arriaza 1999). Por lo tanto, las circunstancias de protección militar y de defensa de derechos de agua, sugeridas para el valle de Chillón, no se habrían repetido en el Lluta. Esto podría estar relacionado con la organización segmentaria sugerida para los grupos de tierras bajas de los Valles Occidentales, a través de cuyo sistema se habrían encadenado una serie de asentamientos a lo largo del valle de Lluta, con grupos de población ligados por lazos de parentesco o adscripción y por acuerdos entre los líderes de cada colectividad. A partir de esta red social se establecían las relaciones de colaboración, protección, traspaso de bienes y recursos, intercambios de esposas y esposos.

Un tercer escenario sería que el chaupiyunga fue ocupado mayoritaria o exclusivamente por población de tierras bajas, y que la introducción de bienes y productos importados (i.e. de tierras altas) se explicaría por el intercambio impulsado por el tráfico caravanero, bien reflejado en sitios de grabados rupestres y geoglifos del valle. Este escenario no implicó necesariamente la co-residencia o la inmigración de pequeños núcleos de población serrana o altiplánica, aunque ésta pudo ocurrir simultáneamente a la operación del tráfico caravanero, lo que no se condice con la evidencia bioantropológica local que muestra cierto nivel de miscegenación favoreciendo los escenarios que implican el ingreso y asentamiento de gente.

Desde un punto de vista diacrónico, es importante detenerse en la exacerbación de los componentes locales en contextos funerarios del período Tardío, que contrasta con una notoria baja de inhumaciones con ofrendas funerarias de elementos de tierras altas, diferencia que no se observa en el Intermedio Tardío. Pensamos que esto podría estar ligado a los cambios económicos y políticos operados por el Inka que limitaron las redes de tráfico y acceso fluido de población e ítems de tierras altas al chaupiyunga, algo ya propuesto tentativamente por Llagostera (1976). Este descenso del componente de tierras altas coincide por otro lado con el hecho que la población tendió a concentrarse en el sector fértil del valle, donde se verifica el asentamiento Molle Pampa Este (L1-66) cuya superficie de actividad doméstica supera las 10 hectáreas, una anomalía notable en relación a los asentamientos del Intermedio Tardío de los valles de Arica. 
Finalmente, la aplicación de modelos de agencia podría ser una alternativa adicional más apropiada para los tipos de interacción intergrupal relatados en este estudio. Los modelos de agencia suponen alternativas de estructuras y de organización que responden a situaciones y condiciones específicas, por lo que se orientan a la selección y consecución de objetivos por parte de los agentes (Bourdieu 1979; Giddens 1995; Hodder 1979, 2000; Saitta 1994; Shanks y Tilley 1987). En ellos, la base de la acciones involucra una complejidad de motivos, cálculos y negociaciones entre los grupos en competencia. Vale decir, grupos individuales son modelados como actores en lo que ellos piensan les permitirán conseguir sus objetivos específicos y elegir estrategias para hacer prevalecer sus organizaciones, dependiendo de la situación concreta y si esto tiene que ver con intercambio de productos, alianzas matrimoniales, conflictos, derechos de agua, corresidencia, verticalidad y otros patrones de interacción intergrupales (ver p.ej., Knudson y Buikstra 2007). Modelos de agencia y de interacción no implican que los grupos de los valles perdieron su identidad comunitaria como consecuencia de esos arreglos. Sin embargo, debieron existir cambios de identidades entre los grupos involucrados en la medida que los arreglos socio-económicos implicaron traspasos de poder de un grupo a otro, a través del tiempo y del espacio (Platt 2010).

Agradecimientos: Estudio financiado por los proyectos FONDECYT 1000457/ 1030312 y 1095006 , 1071132, Beca CONICYT AT-24071027, Centro de Investigaciones del Hombre en el Desierto (CIHDE) y Convenio de Desempeño UTA/MECESUP 2. A María Rostworowski por su oportuna y amable respuesta a consultas sobre los grupos yungas de la costa central de Perú. A los cuatro evaluadores anónimos cuyas sugerencias y comentarios críticos fueron cruciales para darle mayor coherencia y sustentación al manuscrito. La edición final se realizó en Dumbarton Oaks Washington D.C., gracias a una beca Fellow 2009-2010 al primer autor.

\section{Referencias Citadas}

Barnard A. y J. Spencer

1996 Encyclopedia of Social and Cultural Anthropology. Routledge, London \& New York.

Bourdieu, P.

1979 La Distinction. Minuit, París.

Covey, R.A.

2000 Inka administration of the far south coast of Peru. Latin American Antiquity 11:119-138.

Craig, A.K.

1985 Cis-Andean environmental transects. Late Quaternary ecology of northern and southern Peru. En Andean Ecology and Civilization an Interdisciplinary Perspective on Andean Ecological Complementarity, editado por Sh. Masuda, I. Shimada y C. Morris, pp. 23-43. University of Tokyo Press, Tokyo.

D'Altroy, T.N.

1992 Provincial Power in the Inka Empire. Smithsonian Institution Press, Washington and London.

Dillehay, T.D.

1976 Competition and Cooperation in a Prehispanic MultiEthnic System in the Central Andes. Unpublished Ph.D. Dissertation, The University of Texas, Austin.

1979 Prehispanic resource sharing in the central Andes. Science 204(6):24-31.

1987 Estrategias políticas y económicas de las etnias locales del valle de Chillón durante el período prehispánico. Revista Andina 5:407-456.

Dillehay T.D., V.I. Williams y C.M. Santoro

2006 Áreas periféricas y nucleares. Contextos de interacciones sociales complejas y Multidireccionales. Chungara Revista de Antropología Chilena 38:249-256.
Durston, A. y J. Hidalgo

1997 La presencia andina en los valles de Arica, siglos XVI-XVIII. Casos de regeneración colonial de estructuras archipielágicas. Chungara 29:249-273.

Espoueys, O., V. Schiappacasse, J. Berenguer y M. Uribe 1995 En torno al surgimiento de la Cultura Arica. Actas del XIII Congreso Nacional de Arqueología Chilena, Tomo 1, pp. 171-184.

Evans-Pritchard, E.E.

1960 The Nuer: A Description of the Modes of Livelihood and Political Institutions of a Nilotic People. Clarendon Press, Oxford.

Feinman, G.

2000 Corporate/Network. New perspectives on models of political action and the Puebloan Southwest. En Social Theory in Archaeology, editado por M. Schiffer, pp. 31-51. The University of Utah Press, Salt Lake City.

Giddens, A.

1995 La Constitución de la Sociedad: Bases para la Teoría de la Estructuración. Amorrortu Editores, Buenos Aires.

Hidalgo, J.

1982 Culturas y etnias protohistóricas: área andina meridional. Chungara 8:209-252.

2004 Historia Andina en Chile. Editorial Universitaria, Santiago.

2009 Los pescadores de la costa norte de Chile y su relación con los agricultores, siglos dieciséis y diecisiete. En La Arqueología y la Etnohistoria. Un Encuentro Andino, editado por J.R. Topic, pp. 143-196. Serie: Historia Andina, 37. IEP Instituto de Estudios Peruanos; IAR Institute of Andean Research. Lima-New York. 
Hidalgo, J., P. Arévalo, M. Marsilli y C. Santoro

1988 Padrón de la doctrina de Belén en 1813: Un caso de complementariedad tardía. Documento de Trabajo 4, Universidad de Tarapacá, Arica.

Hidalgo, J. y A. Durston

1998 Reconstitución étnica colonial en la sierra de Arica. El cacicazgo de Codpa, 1650-1780. Actas del IV Congreso Internacional de Etnohistoria, Tomo II, pp. 32-75. Pontificia Universidad Católica del Perú, Lima.

Hidalgo, J., A. Durston, V. Briones y N. Castro

1997 El cacicazgo de Tacna; un proceso de etnogénesis colonial siglos XVI-XVIII. Actas del XIV Congreso nacional de Arqueología Chilena. Contribución Arqueológica 5:251-268.

Hidalgo, J. y G. Focacci

1986 Multietnicidad en Arica, S. XVI. Evidencias etnohistóricas y arqueológicas. Chungara 16/17:137-147.

Hodder, I.

1979 Social and economic stress and material culture patterning. American Antiquity 44(3):446-454.

2000 Agency and individuals in long-term processes. En Agency in Archaeology, editado por M. Dobres y J. Robb, pp. 21-33. Routledge, London.

Horta, H. y C. Agüero

2009 Estilo, iconografía y función de las inkuñas prehispánicas del norte de Chile durante el periodo Intermedio Tardío (1.000-1.470 d.C.). Chungara Revista de Antropología Chilena 41:183-227.

Julien, C.J.

1985 Guano and resource control in sixteenth-century Arequipa. En Andean Ecology and Civilization an Interdisciplinary Perspective on Andean Ecological Complementarity, editado por Sh. Masuda, I. Shimada y C. Morris, pp. 185-231. University of Tokyo Press, Tokyo.

Knudson, K.J. y J.E. Buikstra

2007 Residential mobility and resource use in the Chiribaya polity of Southern Peru: Strontium isotope analysis of archaeological tooth enamel and bone. International Journal of Osteoarchaeology 17:563-580.

Lozada M.C. y J.E. Buikstra

2002 El Señorío de Chiribaya en la Costa Sur del Perú. Instituto de Estudios Peruanos, Lima.

Lozada, M.C., J. Lazo, y J.E. Buikstra

2009 El señor y el curandero: Patrones funerarios Chiribaya en el extremo sur de Perú. Andes (Boletín del Centro de Estudios Precolombinos de la Universidad de Varsovia) 7:97-110.

Lumbreras, L.G.

1981 Arqueología de la América Andina. Editorial Milla Batres, Lima.

Llagostera, A.

1976 Hipótesis sobre la expansión incaica en la vertiente occidental de los Andes meridionales. En Homenaje al Dr. Gustavo Le Paige S.J., editado por H. Niemeyer, pp. 203218. Universidad del Norte, Antofagasta.

2010 Retomando los límites y las limitaciones del "archipiélago vertical”. Chungara Revista de Antropología Chilena 42:283-295.

Muñoz, I.

1987 La Cultura Arica: un intento de visualización de relaciones de complementariedad económica-social. Diálogo Andino 6:29-43.
Muñoz, I., J. Chacama, G. Espinosa y L. Briones

1987 La ocupación prehispánica tardía en Zapahuira y su vinculación a la organización económica y social Inca. Chungara 18:67-89.

Muñoz, I., J. Chacama y M. Santos

1997 Tambos, Pukaras y Aldeas, evidencias del poblamiento humano prehispánico tardío y de contacto indígena-europeo en el extremo norte de Chile: análisis de los patrones habitacionales y nuevas dataciones radiométricas. Diálogo Andino 16:123-191.

Muñoz, I. y M. Santos

2000 El poblamiento local de Pubrisa y la interacción en el valle de Azapa. Pacarina 1:6-48.

Murra, J.

1964a Una apreciación etnológica de la Visita. En Visita Hecha a la Provincia de Huanuco por Garci Diez de San Miguel en el año 1567, editado por Waldemar Espinoza Soriano, pp. 419-442. Casa de la Cultura del Perú, Lima.

1964b An archaeological re-study of an Andean ethnohistorical account. American Antiquity 28:1-4.

1968 An aymara kingdom in 1567. Ethnohistory 15:115-151.

1972 El "control vertical" de un máximo de pisos ecológicos en la economía de las sociedades andinas. En Visita de la Provincia de León de Huanuco en 1562. Iñigo Ortiz de Zúñiga, Visitador, volumen 2, editado por J.V. Murra, pp. 429-476. Universidad Hermilio Valdizan, Huánuco.

1976 Los límites y la limitaciones del "archipiélago vertical" en los Andes. En Homenaje al R. P. Gustavo Le Paige S.J., editado por H. Niemeyer, pp. 141-146. Universidad del Norte, Antofagasta.

1985 The limits and limitations of the "vertical archipelago" in the Andes. En Andean Ecology and Civilization, an Interdisciplinary Perspective on Andean Ecological Complementarity, editado por S. Masuda, I. Shimada y C. Morris, pp. 15-20. University of Tokyo Press, Tokyo.

Nielsen, A.

2006a Pobres Jefes: Aspectos Corporativos en las Formaciones Sociales Pre-Inkaicas de los Andes Circumpuneños. En Contra la Tiranía Tipológica en Arqueología: Una Visión desde Sudamérica, editado por Cristóbal Gnecco y Carl Langebaek, pp. 120-150. Universidad de los Andes, Ediciones Uniandes, Bogotá.

2006b Plazas para los antepasados: Descentralización y poder corporativo en las formaciones políticas preincaicas de los Andes circumpuneños. Estudios Atacameños 31:63-89.

Núñez, L. y T. Dillehay

1995 Movilidad Giratoria, Armonía Social y Desarrollo en los Andes Meridionales: Patrones de Tráfico e Interacción Económica. Universidad de Norte, Antofagasta.

Pärssinen, M. y A. Siiriäinen

1997 Inka-Style ceramics and their chronological relationship to the Inka expansion in the southern Lake Titicaca area (Bolivia). Latin American Antiquity 8:255-271.

Pease, F.

1985 Cases and variation of verticality in the southern Andes. En Andean Ecology and Civilization, an Interdisciplinary Perspective on Andean Ecological Complementarity, editado por Sh. Masuda, I. Shimada y C. Morris, pp. 141-160. University of Tokyo Press, Tokyo.

Platt, T.

2010 "Desde la perspectiva de la isla". Guerra y transformación en un archipiélago vertical andino: Macha (Norte de 
Potosí, Bolivia). Chungara Revista de Antropología Chilena 42:297-324.

Romero, Á.

2005 Organización Social y Economía Política en la Prehistoria Tardía de los Valles de Arica. Memoria para optar al título de Arqueólogo, Facultad de Ciencias Sociales, Universidad de Chile, Santiago.

Romero, Á., C.M. Santoro y M. Santos

2000 Asentamientos y organización sociopolítica en los tramos bajo y medio del valle de Lluta. Actas del Tercer Congreso Chileno de Antropología, Tomo II, pp. 696-706.

Rostworowski, M.

1972 Etnias Guancayo en el valle del Chillón. Revista del Museo Nacional de Lima 38:250-314.

1973 Las etnias del valle de Chillón. Revista del Museo Nacional de Lima 38:253-265.

1981 Recursos Naturales Renovables y Pesca, siglos XVI y XVII. Instituto de Estudios Peruanos, Lima.

1986 La región del Colesuyu. Chungara 16/17:127-135.

1989 Costa Peruana Prehispánica (segunda edición). Instituto de Estudios Peruanos, Lima.

Rothhammer, F. y J.A. Cocilovo

2008 Microdiferenciación craneana en la costa de Arica y valle de Azapa, norte de Chile. Resumen de resultados y conclusiones. Chungara Revista de Antropología Chilena 40:309-315.

Rothhammer, F. y C.M. Santoro

2001 El desarrollo cultural en el valle de Azapa, extremo norte de Chile y su vinculación con los desplazamientos poblacionales altiplánicos. Latin American Antiquity 12:59-66.

Sahlins, M.D.

1961 The Segmentary Lineage: An Organization of Predatory Expansion. American Anthropologist 63:322-345.

Saitta, D.J.

1994 Agency, class, and archaeological interpretation. Journal of Anthropological Archaeology 13(3):201-227.

Santoro, C.M.

1995 Late Prehistoric Regional Interaction and Social Change in a Coastal Valley of Northern Chile. Ph.D. dissertation, Department of Anthropology, University of Pittsburgh, Pittsburgh.

Santoro, C., J. Hidalgo, y A. Osorio

1989 El estado Inka y el sistema hidráulico de Socoroma. Chungara 19:71-92.

Santoro, C., Á. Romero y M. Santos

2001 Formas cerámicas e interacción regional durante los períodos Intermedio Tardío y Tardío en el valle de Lluta. En Segundas Jornadas de Arte y Arqueología, editado por J. Berenguer, L. Cornejo; F. Gallardo y C. Sinclaire, pp. 15-40. Museo Chileno de Arte Precolombino, Santiago.

Santoro, C.M., Á. Romero, V. Standen y A. Torres 2004 Continuidad y cambio en las comunidades locales, períodos Intermedio Tardío y Tardío, Valles Occidentales del Área Centro Sur Andina. Chungara Revista de Antropología Chilena Volumen Especial, Tomo I:235-247.

Santoro, C.M., Á. Romero G. y V.G. Standen y D. Valenzuela 2009 Interacción Social en los Períodos Intermedio Tardío y Tardío, Valle de Lluta, Norte de Chile. En La Arqueología y la Etnohistoria: Un Encuentro Andino, editado por J. Topic, pp. 81-136. Instituto de Estudios Peruanos, Lima.
Schiappacasse, V.

1999 Cronología del Estadio Inca. Estudios Atacameños 18:133-140.

Schiappacasse, V., V. Castro y H. Niemeyer

1989 Los desarrollos regionales en el norte grande (1000 a 1400 d.C.). En Culturas de Chile, Prehistoria desde los Orígenes hasta los Albores de la Conquista, editado por J. Hidalgo, V. Schiappacasse, H. Niemeyer, C. Aldunate e I. Solimano, pp. 181-220. Andrés Bello, Santiago.

Schiappacasse, V. y H. Niemeyer

1989 Avances y sugerencias para el conocimiento de la prehistoria tardía de la desembocadura del valle de Camarones (Región Tarapacá). Chungara 22:63-84.

2002 Ceremonial Inca Provincial: el asentamiento de Saguara (valle de Camarones). Chungara Revista de Antropología Chilena 34:53-84.

Shanks, M. y C. Tilley

1987 Re-constructing Archaeology: Theory and Practice. Routledge, London.

Shimada, I.

1982 Horizontal archipelago and coast-highland interaction in north Peru: Archaeological models. Senri Ethonological Studies 10:137-210.

Standen, V.G. y B.T. Arriaza

1999 Traumas en las poblaciones Chinchorros (costa norte de Chile): ¿Violencia o situaciones accidentales? Chungara 29:133-150.

Stanish, Ch.

1989 Household archeology. Testing models of zonal complementarity in the South Central Andes. American Anthropologist 91:7-24.

1992 Ancient Andean Political Economy. University of Texas Press, Austin.

Sutter, R.C.y L Mertz

2004 Nonmetric cranial trait variation and prehistoric biocultural change in the Azapa Valley, Chile. American Journal of Physical Anthropology 123:130-145.

Uribe, $\mathrm{M}$.

1995 Cerámica arqueológica de Arica (extremo norte de Chile): Primera etapa de una reevaluación tipológica. Actas del XIII Congreso Nacional de Arqueología Chilena, Tomo II: 81-96. Hombre y Desierto 9, Antofagasta.

1999 La cerámica de Arica 40 años después de Dauelsberg. Chungara 31:189-228.

2000 Cerámicas arqueológicas de Arica: II etapa de una reevaluación tipológica (períodos Intermedio Tardío y Tardío). Actas del XIV Congreso Nacional de Arqueología Chilena, Tomo II: 13-44. Contribución Arqueológica 5. Museo Regional de Atacama, Copiapó.

Valenzuela, D.

2004 Imágenes sobre Piedra y Tierra: las sociedades del valle de Lluta, períodos Intermedio Tardío y Tardío. Memoria para optar al título de arqueóloga. Departamento de Antropología, Universidad de Chile, Santiago.

Valenzuela, D., Á. Romero y C.M. Santoro

2004 Arte rupestre en asentamientos del período Inka en los valles de Lluta y Azapa, norte de Chile. Chungara Revista de Antropología Chilena 36:421-437.

Valenzuela, D., L Briones y C. Santoro

2006 Arte rupestre en el paisaje: contextos de uso del arte rupestre en el valle de Lluta, norte de Chile, períodos 
Intermedio Tardío y Tardío. En Tramas en la Piedra. Producción y Usos del Arte Rupestre, editado por D. Fiore y M.M. Podestá, pp. 205-220. World Archaeological Congress, Sociedad Argentina de Antropología y Asociación Amigos del Instituto Nacional de Antropología, Buenos Aires.

Valenzuela, D., C. Santoro y L. Briones

2009 Arte Rupestre, Tráfico Caravanero e Interacción Social: cuatro modalidades en el ámbito exorreico de los Valles
Occidentales, Norte de Chile (períodos Intermedio Tardío y Tardío, ca. 1000-1535 d.C.). En Viajeros en Ruta: Arqueología, Historia y Etnografía del Tráfico Surandino, editado por A. Nielsen y L. Núñez. En preparación, manuscrito en poder de los editores).

van Buren, $M$.

1996 Rethinking the Vertical Archipelago. American Anthropologist 98:338-351.

\section{Notas}

1 Al final de su vida, Murra (comunicación personal al primer autor) consideraba que los estudios andinos no tuvieron suficiente colaboración interdisciplinaria entre colegas de distintos países para entender mejor el funcionamiento de las sociedades preindustriales en general y andinas en particular (Murra 1985:4).

2 Ver Shimada (1982) para una revisión crítica del modelo para el norte de Perú, y van Buren (1996), D’Altroy (1992) y Santoro et al. (2009) para el área Centro Sur Andina.

3 El valle de Lluta puede ser dividido en tres grandes zonas: altiplánica, serrana y baja. La zona baja incluye el sector valle costero (0-250 msm), valle fértil (250-950 $\mathrm{msm})$ y valle intermedio chaupiyunga (950-1.800 msm), ver Figura 2.

4 La disparidad en las fechas de inicio del período Tardío o Inka y del período Colonial, en los Andes Centrales (1.300 y 1.520 d.C., respectivamente) y Valles Occidentales de los Andes Centro Sur (1.400 y 1.535 d.C., respectivamente) obedece a las evidencias arqueológicas y documentales disponibles (Dillehay 1987; Pärssinen y Siiriäinen 1997; Santoro 1995; Santoro et al. 2009; Schiappacasse 1999).

5 L1-44 Molinos Oeste, L1-21 Millune Cementerio, L1-22 Millune Oeste Cementerio, L1-41 Chapisca, L1-42 Taipymarca,
Ll-19 Sora Sur, Ll-21 Poblado Millune, Ll-43 Cruces de Molinos, L1-93 Vinto 1-2, L1-92 Vinto 4, L1-91 Arancha, L1-28 Chaquire, L1-96 Sora Norte, L1-40 Intine, Ll-98 Marka Vilavila.

6 Se han definido tres tipos de asentamientos para el valle de Lluta, rotulados como patrón de asentamiento I, II y III (PAI, PAII, PAIII). Estos tipos fueron clasificados de acuerdo al lugar de emplazamiento, el nivel de organización y variedad de componentes funcionales internos (vías de circulación, recintos de almacenaje, tumbas, plataformas, etc.), tamaño, forma y materiales de construcción de los recintos (Romero et al. 2000; Santoro et al. 2009). El PAI se caracteriza por poblados de organización simple con arquitectura de forma cuadrangular construida de caña y totora. El PAII se compone de poblados de organización compleja de recintos rectangulares de caña y totora con vías de circulación y áreas funcionales mejor organizadas espacialmente. Los asentamientos del PAIII son poblados de organización compleja, de recintos circulares socavados, construidos con muros de mampostería de piedra no canteada y sin argamasa.

7 No hay muestra de cementerio asociada al PAII. 